\title{
Impact of high turbidity on reverse osmosis: evaluation of pretreatment processes
}

\author{
Mhd Ammar Hafiz ${ }^{\mathrm{a}}$, Alaa H. Hawari ${ }^{\mathrm{a}, *}$, Ahmed T. Yasira, Radwan Alfahel ${ }^{\mathrm{a}}$, \\ Mohammad K. Hassan ${ }^{\text {, }}$ Ali Altaee ${ }^{\mathrm{c}}$ \\ ${ }^{a}$ Department of Civil and Architectural Engineering, Qatar University, P.O. Box: 2713, Doha, Qatar, email: a.hawari@qu.edu.qa (A.H. Hawari) \\ ${ }^{b}$ Centre for Advanced Materials, Qatar University, P.O. Box: 2713, Doha, Qatar \\ 'School of Civil and Environmental Engineering, University of Technology in Sydney, 15 Broadway, Ultimo, NSW 2007, Australia
}

Received 11 June 2020; Accepted 19 August 2020

\section{A B S T R A C T}

This study evaluates the performance of sand filtration (SF) and ultra-filtration (UF) as pretreatment processes for reverse osmosis (RO) for seawater with turbidities of 4.8, 23.2, and 99.7 NTU. For seawater with a turbidity of 4.8 and $23.2 \mathrm{NTU}$, the average membrane flux and the water recovery rate in the $\mathrm{RO}$ process did not improve significantly by pretreating the seawater using SF or UF. However, when the turbidity of seawater was 99.7 NTU, pretreating the seawater with UF improved the average membrane flux and the water recovery rate in the RO process by $5 \mathrm{LMH}$ and $1.7 \%$, respectively. Pretreatment of seawater with a turbidity of 99.7 NTU with UF reduces the specific energy demand and increases the average membrane flux and water recovery rate.

Keywords: Reverse osmosis; Pretreatment; Ultrafiltration; Sand filtration; Turbidity removal; Desalination 